\title{
Which early 'red flag' symptoms identify children with meningococcal disease in primary care?
}

\author{
Tanya Ali Haj-Hassan, Matthew J Thompson, Richard T Mayon-White, Nelly Ninis,
} Anthony Harnden, Lindsay FP Smith, Rafael Perera and David C Mant

\section{ABSTRACT}

\section{Background}

Symptoms are part of the initial evaluation of children with acute illness, and are often used to help identify those who may have serious infections. Meningococcal disease is a rapidly progressive infection that needs to be recognised early among children presenting to primary care.

Aim

To determine the diagnostic value of presenting symptoms in primary care for meningococcal disease.

Design of study

Data on a series of presenting symptoms were collected using a parental symptoms checklist at point of care for children presenting to a GP with acute infection.

Symptom frequencies were compared with existing data on the pre-hospital features of 345 children with meningococcal disease.

Setting

UK primary care.

\section{Method}

The study recruited a total of 1212 children aged under 16 years presenting to their GP with an acute illness, of whom 924 had an acute self-limiting infection, including 407 who were reported by parents to be febrile. Symptom frequencies were compared with those reported by parents of 345 children with meningococcal disease. Main outcome measures were diagnostic characteristics of individual symptoms for meningococcal disease.

Results

Five symptoms have clinically useful positive likelihood ratios $(\mathrm{LR}+)$ for meningococcal disease: confusion $(\mathrm{LR}+=24.2,95 \%$ confidence interval $[\mathrm{Cl}]=11.5$ to 51.3$)$, leg pain ( $\mathrm{LR}+=7.6,95 \% \mathrm{Cl}=4.9$ to 11.9 ), photophobia $(\mathrm{LR}+=6.5,95 \% \mathrm{Cl}=3.8$ to 11.0$)$, rash $(\mathrm{LR}+=5.5,95 \%$ $\mathrm{Cl}=4.3$ to 7.1 ), and neck pain/stiffness ( $\mathrm{LR}+=5.3,95 \%$ $\mathrm{Cl}=3.5$ to 8.3). Cold hands and feet had limited diagnostic value ( $\mathrm{LR}+=2.3,95 \% \mathrm{Cl}=1.9$ to 3.0 ), while headache $(\mathrm{LR}+=1.0,95 \% \mathrm{Cl}=0.8$ to 1.3$)$, and pale colour ( $\mathrm{LR}+=0.3,95 \% \mathrm{Cl}=0.2$ to 0.5 ) did not discriminate meningococcal disease in children.

\section{Conclusion}

This study confirms the diagnostic value of classic 'red flag' symptoms of neck stiffness, rash, and photophobia, but also suggests that the presence of confusion or leg pain in a child with an unexplained acute febrile illness should also usually prompt a face-to-face assessment to exclude meningococcal disease. Telephone triage systems and primary care clinicians should consider these as 'red flags' for serious infection.

Keywords

children; diagnosis; meningococcal infections; primary care; symptoms.

\section{INTRODUCTION}

Identifying a child who may have a serious infection among those presenting with minor or self-limiting illness is challenging for primary care clinicians, and is a recurrent worry for parents of young children. The vast majority of infections in primary care are minor or self-limiting, yet infections are a dynamic process, and some children with serious bacterial infections will present initially with non-specific clinical features. ${ }^{1,2}$ The meningococcal $\mathrm{C}$ vaccination programme has virtually wiped out meningococcal $\mathrm{C}$ infection; however, meningococcal disease is still the most important infectious cause of death in children and young people in the UK, due to meningococcal $\mathrm{B}$ infection. ${ }^{3}$

Unfortunately, approximately half of children with meningococcal disease are not identified at the first

TA Haj-Hassan, BA, MSc (Global Health Science), MSc (Primary Health Care), medical student; RT Mayon-White, FRCP, FFPH, epidemiologist; A Harnden, FRCGP, FRCPCH, university lecturer; $R$ Perera, $M S c$, DPhil, university lecturer in statistics; DC Mant, FRCGP, FRCP, FMS, professor of general practice, Oxford University Department of Primary Health Care, Oxford. MJ Thompson, MPH, DPhil, MRCGP, senior clinical scientist and GP, Oxford University Department of Primary Health Care, Oxford, and Department of Family Medicine, Oregon Health and Science University, Portland, Oregon, US. N Ninis, MRCP, MD, consultant paediatrician, Imperial College Healthcare NHS Trust, London. LFP Smith, $M D, P h D, F R C P$, FRCGP, FHEAGP, West Coker Surgery and East Somerset Research Consortium, Somerset.

Address for correspondence

Dr Matthew J Thompson, Department of Family Medicine, Oregon Health and Science University, 3181 SW Sam Jackson Park Road, Mailcode FM, Portland, OR 97239, US.

E-mail: thompmat@ohsu.edu

Submitted: 15 August 2010; Editor's response: 7 September 2010; final acceptance: 5 October 2010.

(C)British Journal of General Practice

This is the full-length article (published online $28 \mathrm{Feb} 2011$ ) of an abridged version published in print. Cite this article as: Br J Gen Pract 2011; DOI: 10.3399/bjgp11X561131. 
consultation in primary care. ${ }^{1,4-6}$ Systematic assessments of the clinical features of children with meningococcal disease have found that the classic features (for example, neck stiffness, photophobia, petechial rash) may appear late in the pre-hospital course of the illness. ${ }^{1,7}$ However, several possible 'red flag' clinical features (leg pain, cold hands and feet, and abnormal skin colour) have previously been identified, which occur up to 11 hours before hospital admission. ${ }^{1}$

The history is usually the most important part of a clinical assessment, so it is vital that clinicians have evidence to determine which symptoms are useful to discriminate serious from less serious illness. Telephone triage is now a common part of primary care practice, and is often used to determine whether a child needs to be examined face to face. Although it is useful to know the frequency of various symptoms in children with serious illnesses such as meningococcal disease, in order to assess their diagnostic value we also need to know how frequently they occur in children with minor or selflimiting infections. This is currently an important research gap, highlighted by National Institute for Health and Clinical Excellence and Scottish Intercollegiate Guidelines Network guidelines on the management of feverish illness and meningococcal disease. ${ }^{8,9}$ This paper describes the results of a prospective cross-sectional study to determine the frequency of presenting symptoms in children attending primary care with acute infections. The frequency of classic meningitis symptoms and the 'red flag' features of cold hands and feet, leg pain, and pale colour in children with minor febrile illness in primary care were compared with existing data on children with meningococcal disease, to determine the diagnostic value of individual symptoms.

\section{METHOD}

\section{Children with self-limiting infections}

Participants. Children between 1 month and 16 years of age presenting in primary care with acute illness were recruited from GP surgeries in Oxfordshire and Somerset. Children were eligible for inclusion if they were under 16 years of age, accompanied by an adult caregiver who was able to provide informed consent, and attending an acute appointment (made within the previous 72 hours).

Sampling period. To avoid the potential confounding effects of season on the incidence of certain symptoms (for example, cold hands and feet), and to enhance the comparability of the data with the existing meningococcal disease dataset, children were recruited at a similar seasonal rate to that found in the meningococcal disease study, ${ }^{1}$ in 20

\section{How this fits in}

Meningococcal disease is an important cause of mortality in children, and is difficult to diagnose in its early stages. Classic features of meningism, such as neck stiffness, photophobia, and haemorrhagic rash, are late features in the pre-hospital presentation of this disease. Leg pain, cold hands and feet, and pale colour have been suggested as 'red flag' features of early meningococcal sepsis. This study compared the frequency of presenting symptoms in children with minor self-limiting febrile infections with their frequency in children with meningococcal disease. Children with minor febrile illnesses in primary care are unlikely to present with symptoms such as confusion, photophobia, neck pain/stiffness, or leg pain. These symptoms all have clinically useful positive likelihood ratios for meningococcal disease and should be considered as 'red flags' for this illness. These symptoms should be used in the assessment of children with serious infections in primary care settings and, when present, should usually prompt a face-to-face assessment.

sampling periods of 1-week's duration between June 2007 and July 2009.

Data collection. Receptionists at participating practices were asked to distribute 30 questionnaires to potential study participants during each recruitment week. The questionnaire listed 25 symptoms, and parents were asked to mark the symptoms their child was currently experiencing, the symptom of most concern to them, and the duration of illness. The symptoms selected for the questionnaire were based on those included in the meningococcal disease study ${ }^{1}$ as well as several non-specific symptoms that are common to childhood illnesses.

After completing the questionnaire, parents could hand it to their GP during the consultation, return it to the receptionist after the consultation, or post it to the investigator. Each child's medical record was reviewed by a researcher to retrieve details of the consultation and final diagnosis, as well as any urgent hospital referral on the day of consultation or in the subsequent 2 weeks.

Data entry. Data were entered into a Microsoft Access $^{\circledR}$ database. The diagnosis recorded by the GP during the consultation was noted. If missing, the diagnosis was determined by consensus between the authors based on the child's clinical presentation. Children with a final diagnosis that was not consistent with an acute infection (for example, minor trauma, atopic eczema, asthma, allergic rhinitis, infantile colic) were excluded, as well as those for whom there was insufficient information to determine a diagnosis. Any children who may have had a serious illness, which was defined as those who were referred acutely to hospital (emergency department or admission) within the subsequent 2 weeks, were also excluded. The frequency of 
clinical features was determined in the subgroup of children presenting with minor febrile infections, which was defined as any acute infection in which the parent indicated on the symptoms questionnaire that fever was present in their current illness.

\section{Children with meningococcal disease}

The frequency of clinical features in children with meningococcal disease prior to hospital admission was obtained from a study of 448 children that has been described previously. ${ }^{1,10}$ Between 1997 and 1999, children who died of meningococcal disease were identified and matched by age group and region of the country with three survivors of meningococcal disease. A total of 448 children (103 fatal, 345 non-fatal) aged 16 years or younger were included in the final study, of whom 296 (66\%) had predominantly septicaemia, 99 (22\%) meningitis, and $53(12 \%)$ features of both. Data on the frequency of clinical features prior to hospital admission were obtained from detailed questionnaires completed by parents by post $(n=313,69.9 \%)$ or during personal interview $(n=135,30.1 \%)$.

The design of this study (matching fatal cases with non-fatal controls) resulted in an oversampling of deaths for the purposes of the study, with a potential bias towards severe septicaemic disease. To estimate the frequency of clinical features in a balanced sample of children with meningococcal disease that would be seen in practice, the observed (raw) symptom frequency data were weighted to reflect UK casefatality rates. Age-specific case-fatality rates from the Enhanced Surveillance Scheme for Suspected Meningococcal Disease for the epidemiological year 1999 (1 July 1999 to 30 June 2000) were used, ${ }^{11}$ and weighted mean frequencies were calculated for each symptom based on the following formula:

Weighted mean frequency $=$ (mean frequency in fatal cases $x$ age-specific case-fatality rate) + (mean frequency in non-fatal cases $x[1$ - agespecific case-fatality rate]). ${ }^{1}$

\section{Table 1. Characteristics of children in} each study sample.

\begin{tabular}{lcc} 
& $\begin{array}{c}\text { Minor infection in } \\
\text { primary care, } n(\%)\end{array}$ & $\begin{array}{c}\text { Meningococcal } \\
\text { disease, } n(\%)^{\text {a }}\end{array}$ \\
\hline Number of children & 407 & 345 \\
\hline Sex & & \\
$\quad$ Male & $209(51.4)$ & $188(54.5)$ \\
Female & $198(48.6)$ & $157(45.5)$ \\
\hline Age, years & & \\
$<1$ & $41(10.1)$ & $95(27.5)$ \\
$1-4$ & $213(52.3)$ & $155(44.9)$ \\
$5-14$ & $153(37.6)$ & $95(27.5)$ \\
\hline
\end{tabular}

${ }^{\text {a } D a t a}$ derived from reference 1.

\section{Diagnostic value of symptoms in predicting meningococcal disease}

The frequency of symptoms obtained from the cross-sectional study of children attending primary care with acute self-limiting febrile infection was compared with the frequency of symptoms in children with meningococcal disease, using both the observed and case-fatality rate-adjusted symptom frequencies. The resulting $2 \times 2$ contingency tables were used to calculate sensitivities, specificities, and positive and negative likelihood ratios (LRs) and 95\% confidence intervals (Cls). Several symptoms that the authors of the meningococcal paper had considered age specific were analysed only in children over 1 year of age, namely leg pain, headache, and confusion. Responses to the two questions regarding nausea and vomiting were also aggregated to a single variable: nausea and/or vomiting. In addition, as questions on the presence of several non-specific symptoms (coughing for $>2$ weeks, runny nose, earache, wheeze, difficulty sleeping) were not included in the original meningococcal database, it was not possible to use these in the contingency tables. Diagnostic characteristics for all age groups combined were examined, and also stratified for each of three predetermined age groups: <1 year, 1-4 years, and 5-14 years, to explore any potential variations in diagnostic accuracy by age group.

\section{RESULTS}

Description of children recruited from primary care with minor infection

The study recruited a total of 1212 children from 15 GP surgeries in Oxfordshire and Somerset, and excluded those who did not have a final diagnosis consistent with an acute infection $(n=236)$, had no diagnosis listed $(n=16)$, or were admitted or referred to hospital or an emergency department within 1 week of the initial consultation and thus considered possible serious infections $(n=24)$. Only 12 children were recruited in the 15-16 years age group, and this age group was excluded from further analysis. The remaining 924 children (ages 1 month to 14 years 11 months) were recruited from 12 GP surgeries in Somerset $(n=687,74.4 \%)$ and three GP surgeries in Oxfordshire $(n=237,25.6 \%)$. Parents reported a history of fever in 407/924 (44.0\%) children, who were defined as having minor febrile infections (Table 1). Approximately half of the 407 children with minor febrile infections ( $n=198,48.6 \%$ ) were female, with median age of 42 months (interquartile range [IQR] = 22-79 months), and median duration of illness reported by parents of 4 days (IQR $=2-6$ days). The most common diagnoses were upper respiratory 
tract infections ( $n=135,33.2 \%$ ), followed by acute otitis media ( $n=62,15.2 \%$ ), and tonsillitis or pharyngitis $(n=57,14.0 \%$ ) (Table 2 ).

\section{Frequency of symptoms in children with minor febrile infections in primary care}

The most frequent symptoms reported by parents of the 407 children with minor febrile infections were cough ( $n=268,65.8 \%)$, runny nose $(n=244$, $60.0 \%$ ), being irritable/miserable ( $n=213,52.3 \%$ ), sore throat $(198,48.6 \%)$, difficulty sleeping $(n=183$, $45.0 \%)$, refusing food or feeds ( $n=181,44.5 \%)$, and pale colour $(n=169,41.5 \%)$. Of these, the symptoms that parents reported as most concerning to them were cough ( $n=91,22.4 \%$ ), followed by fever $(n=73,17.9 \%)$ and earache $(n=41,10.3 \%)$.

The classic meningeal symptoms of 'hurts to look at lights' (which is referred to as here 'photophobia') and neck pain/stiffness were present in only $3.9 \%$ and $5.7 \%$ respectively of children with minor febrile infections, and headache was reported in approximately one-third (35.5\%) (Table 3 ). The majority of children whose parents reported photophobia had upper respiratory tract infections $(12 / 21,57.1 \%)$, while the remaining nine children had a variety of diagnoses including fever of
Table 2. Diagnosis of the 407 children from primary care with acute self-limiting febrile infections.

\begin{tabular}{lc} 
Diagnosis & Frequency, $n(\%)$ \\
\hline URTI & $135(33.2)$ \\
\hline Acute otitis media & $62(15.2)$ \\
\hline Tonsillitis or pharyngitis & $57(14.0)$ \\
\hline Non-specific viral illness & $56(13.8)$ \\
\hline LRTI or pneumonia & $38(9.3)$ \\
\hline Bronchiolitis & $10(2.5)$ \\
\hline Gastroenteritis & $9(2.2)$ \\
\hline UTI & $7(1.7)$ \\
\hline Cellulitis, impetigo, or infected eczema & $5(1.2)$ \\
\hline Non-specific rash & $5(1.2)$ \\
\hline Other skin infection & $3(0.7)$ \\
\hline Other infection & $20(4.9)$ \\
\hline
\end{tabular}

$L R T I=$ lower respiratory tract infection. $U R T I=$ upper respiratory tract infection. UTI = urinary tract infection

unknown origin, non-specific viral illness, and chickenpox. Of those children whose parents reported neck pain or stiffness, the majority also had upper respiratory tract infections $(26 / 39$, $66.7 \%)$ or non-specific viral illness $(7 / 39,17.9 \%)$. Leg pain was infrequent among children with minor

\begin{tabular}{|c|c|c|c|c|}
\hline Symptom & $\begin{array}{l}\text { Minor non-febrile } \\
\text { infections, } n(\%)\end{array}$ & $\begin{array}{c}\text { Minor febrile } \\
\text { infections, } n(\%)\end{array}$ & $\begin{array}{l}\text { Meningococcal } \\
\text { disease, } n(\%)\end{array}$ & $\begin{array}{c}\text { Meningococcal } \\
\text { disease, adjusted \%a }\end{array}$ \\
\hline \multicolumn{5}{|l|}{ Classic meningeal features } \\
\hline Photophobia & $5 / 517(1.0)$ & 16/407 (3.9) & $73 / 345$ (21.2) & 25.5 \\
\hline Neck pain or stiffness & $16 / 517(3.1)$ & $23 / 407(5.7)$ & 86/345 (24.9) & 30.3 \\
\hline Headache $^{b}$ & $56 / 430(13.0)$ & 130/366 (35.5) & $79 / 250(31.6)$ & 35.1 \\
\hline \multicolumn{5}{|l|}{ Suggested red flags } \\
\hline Leg pain ${ }^{b}$ & $16 / 430(3.7)$ & $21 / 366(5.7)$ & $94 / 250(37.6)$ & 43.8 \\
\hline Cold hands and feet & $23 / 517(4.4)$ & $74 / 407$ (18.2) & $139 / 345$ (40.3) & 43.1 \\
\hline Pale colour & $73 / 517(14.1)$ & $169 / 407(41.5)$ & $65 / 345(18.8)$ & 14.0 \\
\hline \multicolumn{5}{|l|}{ Other features } \\
\hline Confusion $^{\mathrm{b}}$ & $0 / 430(0)$ & $7 / 366$ (1.9) & $101 / 250$ (40.4) & 46.4 \\
\hline Fever or high temperature & $0 / 517(0)$ & $407 / 407$ (100.0) & $323 / 345$ (93.6) & 95.4 \\
\hline Drowsy or very sleepy & $48 / 517(9.3)$ & 142/407 (34.9) & 275/345 (79.7) & 85.5 \\
\hline Rash or new spots on skin ${ }^{c}$ & $90 / 517(17.4)$ & $57 / 407(14.0)$ & $267 / 345$ (77.4) & 77.6 \\
\hline Nausea or vomiting & $78 / 517(15.1)$ & $147 / 407$ (36.1) & $250 / 345$ (72.5) & 72.7 \\
\hline Irritable or miserable & $104 / 517(20.1)$ & $213 / 407$ (52.3) & 236/345 (68.4) & 72.6 \\
\hline General aching & $33 / 517(6.4)$ & $94 / 407(23.1)$ & $129 / 345$ (37.4) & 41.2 \\
\hline Refusing food or feeds & $85 / 517(16.4)$ & $181 / 407(44.5)$ & $200 / 345$ (58.0) & 62.8 \\
\hline Difficult/laboured breathing & $24 / 517(4.6)$ & $54 / 407$ (13.3) & $42 / 345(12.2)$ & 10.5 \\
\hline Diarrhoea & $48 / 517(9.3)$ & $80 / 407$ (19.7) & $35 / 345(10.1)$ & 6.5 \\
\hline Sore throat & $114 / 517(22.1)$ & $198 / 407$ (48.6) & $50 / 345(14.5)$ & 17.0 \\
\hline Tummy pain & 68/517 (13.2) & 95/366 (26.0) & $12 / 250(4.8)$ & 5.7 \\
\hline Cough & $221 / 517(42.7)$ & $268 / 407$ (65.8) & $6 / 345(1.7)$ & 1.9 \\
\hline
\end{tabular}

aStandardised to UK case-fatality rates (CFR) using weighted mean frequency (CFR $=3.6 \%$ for all children $<15$ years; CFR = $3.2 \%$ when children $<1$ year are excluded). ${ }^{b}$ Analysed in children $>1$ year of age. ${ }^{\circ}$ Rash was defined as any type of rash, and in the meningococcal dataset included all rash types mentioned by the parent and/or GP. While this estimate incorporates GP input in some cases and could have overestimated its frequency in the meningococcal dataset (and/or underestimated its frequency in children with minor infections), it is unlikely that a rash was reported by the GP but not reported at all by the parent, and thus the estimated frequency is likely to be representative of parental reporting of this symptom. 
febrile infections (5.7\%), and cold hands and feet were relatively uncommon $(18.2 \%)$. Cold hands and feet were reported in $21.0 \%$ (54/257) of children in winter months, compared with $13.3 \%(20 / 150)$ of children in non-winter months $\left(\chi^{2} P=0.053\right)$.

\section{Description of primary care presentation of children with meningococcal disease}

The frequencies of clinical features noted in the 345 children aged $<15$ years with meningococcal disease are presented as unadjusted (observed) frequencies as well as estimates adjusted for case-fatality rates (Table 3). Most of the frequencies are lower in the observed population than in the adjusted population, with the exception of pale colour, difficult/laboured breathing, and diarrhoea. As reported previously, the majority of children with meningococcal disease had non-specific symptoms such as fever, irritability, nausea, or vomiting. Classic meningitic symptoms, such as neck stiffness and photophobia, were found in approximately one-quarter, and symptoms of cold hands and feet, pale colour, and leg pain in onequarter to one-half of the children.

\section{Comparison of symptom frequency between children with minor febrile infection and meningococcal disease}

Diagnostic characteristics of individual symptoms were calculated using contingency tables of children with minor febrile infections versus the observed and adjusted meningococcal disease frequencies. Estimates of diagnostic accuracy are presented using adjusted frequencies, which are likely to be more conservative (results using the observed frequencies are available from the authors). Drowsiness, rash, nausea or vomiting, and irritability were moderately sensitive for meningococcal disease (Table 4). Four symptoms were highly specific (>90\%) for meningococcal disease: confusion, photophobia, leg pain, and neck pain/stiffness. Symptoms that offered positive LRs $>5.0$ (and are thus likely to be most clinically useful), were: confusion $(L R+=24.2)$, leg pain $(L R+=7.6)$, photophobia $(L R+=6.5)$, rash $(\mathrm{LR}+=5.5)$, and neck pain/stiffness $(\mathrm{LR}+=5.3)$. The only symptoms that offered clinically useful negative likelihood ratios (that is, LR- $\leq 0.3$ ), were drowsiness (LR- $=0.2$ ) and rash $(\mathrm{LR}-=0.3)$, suggesting their absence could exclude or 'rule out' meningococcal disease. Headache and pale colour provided no discrimination between children with meningococcal disease and those with minor febrile infection.

Several symptoms were much more frequent in children with minor febrile illnesses. A cough was present in approximately two-thirds (65.8\%) and sore throat in approximately half $(48.6 \%)$ of children with minor febrile infections, compared to $1.9 \%$ and $14.5 \%$ respectively of children with meningococcal disease. Abdominal pain was present in $26 \%$ with minor febrile illness compared to $4.8 \%$ with meningococcal disease.

The study also explored differences in diagnostic characteristics of individual symptoms in three age groups: <1 year, 1-4 years, and 5-14 years (Table 5). Photophobia and neck stiffness had larger positive LRs in children aged $<1$ year and $1-4$ years than in those aged 5-14 years, but all had wide Cls. Rash had a larger positive LR in older children than in younger children and infants.

\section{Table 4. Diagnostic characteristics of symptoms for meningococcal disease, comparing children with minor febrile infection $(n=407)$ versus case-fatality rate-adjusted meningococcal disease $(n=345)$.}

\begin{tabular}{|c|c|c|c|c|}
\hline Symptom & $\begin{array}{l}\text { Sensitivity, } \\
\%(95 \% \mathrm{Cl})\end{array}$ & $\begin{array}{l}\text { Specificity, } \\
\%(95 \% \mathrm{Cl})\end{array}$ & $\begin{array}{l}\text { Positive likelihood } \\
\text { ratio }(95 \% \mathrm{Cl})\end{array}$ & $\begin{array}{c}\text { Negative likelihood } \\
\text { ratio }(95 \% \mathrm{Cl})\end{array}$ \\
\hline \multicolumn{5}{|l|}{ Classic meningeal features } \\
\hline Photophobia & 25.5 (20.2 to 30.8$)$ & 96.1 (94.2 to 98.0$)$ & 6.5 (3.8 to 11.0$)$ & 0.7 (0.7 to 0.8$)$ \\
\hline Neck pain or stiffness & 30.3 (24.8 to 35.9$)$ & 94.3 (92.1 to 96.6$)$ & 5.3 (3.5 to 8.3$)$ & 0.7 (0.7 to 0.8$)$ \\
\hline Headache & 35.1 (28.3 to 41.9 ) & 64.5 (59.6 to 69.4 ) & $1.0(0.8$ to 1.3$)$ & $1.0(0.9$ to 1.1$)$ \\
\hline \multicolumn{5}{|l|}{ Suggested 'red flag' features } \\
\hline Leg pain & 43.8 (36.7 to 50.8 ) & 94.3 (91.9 to 96.6$)$ & 7.6 (4.9 to 11.9 ) & 0.6 (0.5 to 0.7$)$ \\
\hline Cold hands or feet & 43.1 (37.1 to 49.1$)$ & 81.8 (78.1 to 85.6$)$ & $2.3(1.9$ to 3.0$)$ & 0.7 (0.6 to 0.8$)$ \\
\hline Pale colour & 14.0 (9.8 to 18.3$)$ & 58.5 (53.7 to 63.3$)$ & $0.3(0.2$ to 0.5$)$ & 1.5 (1.3 to 1.6$)$ \\
\hline \multicolumn{5}{|l|}{ Other features } \\
\hline Confusion & 46.4 (39.3 to 53.5$)$ & 98.1 (96.7 to 99.5$)$ & 24.2 (11.5 to 51.3$)$ & 0.5 (0.5 to 0.6$)$ \\
\hline Drowsy or very sleepy & 85.5 (81.3 to 89.8$)$ & 65.1 (60.5 to 69.7$)$ & 2.5 (2.1 to 2.8$)$ & $0.2(0.2$ to 0.3$)$ \\
\hline Rash or new spots on skin & 77.6 (72.5 to 82.7$)$ & 86.0 (82.6 to 89.4$)$ & 5.5 (4.3 to 7.1$)$ & $0.3(0.2$ to 0.3$)$ \\
\hline Nausea or vomiting & 72.7 (67.3 to 78.1$)$ & 63.9 (59.2 to 68.5$)$ & $2.0(1.7$ to 2.3$)$ & $0.4(0.3$ to 0.5$)$ \\
\hline Irritable or miserable & 72.6 (67.1 to 78.0$)$ & 47.7 (42.8 to 52.5$)$ & 1.4 (1.2 to 1.6$)$ & $0.6(0.5$ to 0.7$)$ \\
\hline General aching & 41.2 (35.3 to 47.2$)$ & 76.9 (72.8 to 81.0$)$ & 1.8 (1.4 to 2.2$)$ & $0.8(0.7$ to 0.9$)$ \\
\hline Difficult/laboured breathing & 10.5 (6.8 to 14.3$)$ & 86.7 (83.4 to 90.0$)$ & 0.8 (0.5 to 1.2$)$ & $1.0(1.0$ to 1.1$)$ \\
\hline
\end{tabular}


Table 5. Diagnostic characteristics of symptoms for meningococcal disease stratified by age.

\begin{tabular}{|c|c|c|c|c|c|c|c|}
\hline Symptom & $\begin{array}{l}\text { Age, } \\
\text { years }\end{array}$ & $\begin{array}{l}\text { Minor febrile } \\
\text { infections, \% }\end{array}$ & $\begin{array}{l}\text { Meningococcal dise } \\
\text { adjusted } \%^{\mathrm{a}}\end{array}$ & $\begin{array}{l}\text { ase, Sensitivity, } \\
\%(95 \% \mathrm{Cl})\end{array}$ & $\begin{array}{l}\text { Specificity, } \\
\% \text { (95\% Cl) }\end{array}$ & $\begin{array}{l}\text { Positive likelihood } \\
\text { ratio }(95 \% \mathrm{Cl})\end{array}$ & $\begin{array}{l}\text { Negative likelihooc } \\
\text { ratio }(95 \% \mathrm{Cl})\end{array}$ \\
\hline \multicolumn{8}{|l|}{ Classic meningeal features } \\
\hline \multirow[t]{3}{*}{ Photophobia } & $<1$ & 2.4 & 25.1 & $25.1(15.1$ to 35.1$)$ & 97.6 (92.8 to 102.3 ) & 10.3 (1.4 to 74.2 ) & $0.8(0.7$ to 0.9$)$ \\
\hline & $1-4$ & 2.8 & 25.0 & 25.0 (17.1 to 32.9$)$ & 97.2 (95.0 to 99.4) & 8.9 (3.8 to 20.7$)$ & $0.8(0.7$ to 0.9$)$ \\
\hline & $5-14$ & 5.9 & 26.9 & 26.9 (16.7 to 37.1$)$ & 94.1 (90.4 to 97.8$)$ & 4.6 (2.2 to 9.6$)$ & $0.8(0.7$ to 0.9$)$ \\
\hline \multirow[t]{3}{*}{ Neck pain or stiffness } & $<1$ & 1.2 & 16.3 & 16.3 (7.9 to 24.8$)$ & 98.8 (95.5 to 102.1$)$ & ) 13.7 (0.8 to 226.3 ) & 0.8 (0.8 to 0.9$)$ \\
\hline & $1-4$ & 2.3 & 29.1 & 29.1 (20.9 to 37.4 ) & 97.7 (95.6 to 99.7$)$ & 12.4 (5.0 to 30.9 ) & 0.7 (0.6 to 0.8$)$ \\
\hline & $5-14$ & 11.8 & 47.0 & 47.0 (35.5 to 58.5$)$ & 88.2 (83.1 to 93.3$)$ & $4.0(2.4$ to 6.6$)$ & 0.6 (0.5 to 0.8$)$ \\
\hline \multirow[t]{2}{*}{ Headache } & $1-4$ & 18.5 & 21.9 & 21.9 (14.4 to 29.3 ) & 81.5 (76.3 to 86.7$)$ & $1.2(0.8$ to 1.8$)$ & $1.0(0.9$ to 1.1$)$ \\
\hline & $5-14$ & 59.5 & 56.7 & 56.7 (45.3 to 68.1$)$ & 40.5 (32.7 to 48.3$)$ & $1.0(0.8$ to 1.2$)$ & 1.1 (0.8 to 1.5$)$ \\
\hline \multicolumn{8}{|l|}{ Suggested 'red flag' features } \\
\hline \multirow[t]{2}{*}{ Leg pain } & $1-4$ & 3.3 & 31.7 & $31.7(23.2$ to 40.1$)$ & 96.7 (94.3 to 99.1$)$ & 9.6 (4.4 to 20.9 ) & 0.7 (0.6 to 0.8$)$ \\
\hline & $5-14$ & 9.2 & 63.3 & 63.3 (52.1 to 74.4$)$ & 90.8 (86.3 to 95.4$)$ & 6.9 (4.1 to 11.7$)$ & 0.4 (0.3 to 0.5$)$ \\
\hline \multirow[t]{3}{*}{ Cold hands or feet } & $<1$ & 24.4 & 45.0 & 45.0 (33.5 to 56.4 ) & 75.6 (62.5 to 88.8$)$ & 1.8 (1.0 to 3.3$)$ & 0.7 (0.6 to 1.0$)$ \\
\hline & $1-4$ & 20.2 & 47.0 & 47.0 (37.9 to 56.0 ) & 79.8 (74.4 to 85.2 ) & 2.3 (1.7 to 3.2$)$ & 0.7 (0.6 to 0.8$)$ \\
\hline & $5-14$ & 13.7 & 35.1 & $35.1(24.1$ to 46.1$)$ & $86.3(80.8$ to 91.7$)$ & 2.6 (1.5 to 4.2$)$ & $0.8(0.6$ to 0.9$)$ \\
\hline \multirow[t]{3}{*}{ Pale colour } & $<1$ & 36.6 & 18.7 & $18.7(9.8$ to 27.7$)$ & 63.4 (48.7 to 78.2 ) & $0.5(0.3$ to 1.0$)$ & $1.3(1.0$ to 1.7$)$ \\
\hline & $1-4$ & 38.0 & 9.6 & 9.6 (4.2 to 14.9$)$ & $62.0(55.5$ to 68.5$)$ & 0.3 (0.1 to 0.5$)$ & 1.5 (1.3 to 1.6$)$ \\
\hline & $5-14$ & 47.7 & 16.4 & 16.4 (7.9 to 24.9$)$ & 52.3 (44.4 to 60.2$)$ & $0.3(0.2$ to 0.6$)$ & $1.6(1.3$ to 1.9$)$ \\
\hline \multicolumn{8}{|l|}{ Other features } \\
\hline \multirow[t]{2}{*}{ Confusion } & $1-4$ & 2.3 & 44.2 & 44.2 (35.2 to 53.2 ) & 97.7 (95.6 to 99.7$)$ & $18.8(7.7$ to 45.8$)$ & $0.6(0.5$ to 0.7$)$ \\
\hline & $5-14$ & 1.3 & 49.9 & 49.9 (38.3 to 61.4$)$ & 98.7 (96.9 to 100.5$)$ & ) 38.1 (9.4 to 154.1$)$ & 0.5 (0.4 to 0.6$)$ \\
\hline \multirow[t]{3}{*}{ Drowsy or very sleepy } & $<1$ & 31.7 & 87.7 & 87.7 (80.2 to 95.3$)$ & 68.3 (54.0 to 82.5$)$ & $2.8(1.8$ to 4.4$)$ & $0.2(0.1$ to 0.3$)$ \\
\hline & $1-4$ & 36.2 & 88.7 & 88.7 (83.0 to 94.5$)$ & 63.8 (57.4 to 70.3$)$ & 2.5 (2.0 to 3.0$)$ & 0.2 (0.1 to 0.3$)$ \\
\hline & $5-14$ & 34.0 & 78.2 & 78.2 (68.7 to 87.7$)$ & 66.0 (58.5 to 73.5$)$ & $2.3(1.8$ to 3.0$)$ & $0.3(0.2$ to 0.5$)$ \\
\hline \multirow[t]{3}{*}{ Rash or new spots on skin } & $<1$ & 22.0 & 62.8 & 62.8 (51.7 to 73.9$)$ & 78.0 (65.4 to 90.7$)$ & 2.9 (1.6 to 5.2$)$ & 0.5 (0.3 to 0.7$)$ \\
\hline & $1-4$ & 14.1 & 79.9 & 79.9 (72.6 to 87.2$)$ & 85.9 (81.2 to 90.6$)$ & 5.7 (4.0 to 8.0$)$ & $0.2(0.2$ to 0.3$)$ \\
\hline & $5-14$ & 11.8 & 89.0 & 89.0 (81.8 to 96.2$)$ & 88.2 (83.1 to 93.3 ) & 7.6 (4.9 to 11.8 ) & 0.1 (0.1 to 0.2$)$ \\
\hline \multirow[t]{3}{*}{ Nausea or vomiting } & $<1$ & 39.0 & 53.4 & 53.4 (41.9 to 64.8$)$ & 61.0 (46.0 to 75.9$)$ & $1.4(0.9$ to 2.1$)$ & 0.8 (0.5 to 1.1$)$ \\
\hline & $1-4$ & 35.2 & 76.4 & 76.4 (68.6 to 84.1$)$ & 64.8 (58.4 to 71.2 ) & $2.2(1.8$ to 2.7$)$ & $0.4(0.3$ to 0.5$)$ \\
\hline & $5-14$ & 36.6 & 86.6 & 86.6 (78.7 to 94.4$)$ & 63.4 (55.8 to 71.0$)$ & $2.4(1.9$ to 3.0$)$ & $0.2(0.1$ to 0.4$)$ \\
\hline \multirow[t]{3}{*}{ Irritable or miserable } & $<1$ & 63.4 & 85.0 & 85.0 (76.8 to 93.2$)$ & $36.6(21.8$ to 51.3$)$ & $1.3(1.0$ to 1.7$)$ & $0.4(0.2$ to 0.8$)$ \\
\hline & $1-4$ & 63.8 & 76.4 & 76.4 (68.6 to 84.1$)$ & 36.2 (29.7 to 42.6$)$ & $1.2(1.0$ to 1.4$)$ & $0.7(0.5$ to 0.9$)$ \\
\hline & $5-14$ & 33.3 & 53.8 & 53.8 (42.3 to 65.3 ) & 66.7 (59.2 to 74.1$)$ & 1.6 (1.2 to 2.2$)$ & 0.7 (0.5 to 0.9$)$ \\
\hline \multirow[t]{3}{*}{ General aching } & $<1$ & 12.2 & 22.4 & 22.4 (12.8 to 32.1$)$ & 87.8 (77.8 to 97.8$)$ & 1.8 (0.7 to 4.6$)$ & 0.9 (0.7 to 1.0$)$ \\
\hline & $1-4$ & 17.4 & 39.3 & 39.3 (30.4 to 48.2 ) & 82.6 (77.5 to 87.7$)$ & 2.3 (1.6 to 3.3$)$ & 0.7 (0.6 to 0.9$)$ \\
\hline & $5-14$ & 34.0 & 63.4 & 63.4 (52.3 to 74.5 ) & $66.0(58.5$ to 73.5$)$ & 1.9 (1.4 to 2.5$)$ & 0.6 (0.4 to 0.8$)$ \\
\hline \multirow[t]{3}{*}{ Difficult/laboured breathing } & $<1$ & 19.5 & 16.0 & 16.0 (7.6 to 24.5$)$ & 80.5 (68.4 to 92.6$)$ & $0.8(0.4$ to 1.9$)$ & 1.0 (0.9 to 1.3$)$ \\
\hline & $1-4$ & 14.1 & 9.3 & 9.3 (4.1 to 14.6$)$ & 85.9 (81.2 to 90.6$)$ & $0.7(0.3$ to 1.3$)$ & $1.1(1.0$ to 1.1$)$ \\
\hline & $5-14$ & 10.5 & 6.8 & 6.8 (1.0 to 12.6$)$ & 89.5 (84.7 to 94.4 ) & $0.7(0.2$ to 1.7$)$ & $1.0(1.0$ to 1.1$)$ \\
\hline
\end{tabular}

${ }^{2}$ Standardised to UK case-fatality rates (CFR) using weighted mean frequency (CFR $=4.5 \%$ for children $<1$ year; $3.3 \%$ for children $1-4$ years; $3.0 \%$ for children 5-14 years).

\section{DISCUSSION}

\section{Summary of main findings}

This study provides the first quantification of the diagnostic value of presenting symptoms for meningococcal disease in children presenting with acute infections in primary care. The frequency of presenting symptoms in children with minor acute infections was obtained using a cross-sectional study, and these were compared with previously reported frequencies in children with meningococcal disease. Symptoms that are likely to be valuable as a 'screening tool' for febrile children in primary care should ideally have a high sensitivity. Only drowsiness was moderately sensitive (85\%) for meningococcal disease. By contrast, four symptoms were found that were highly specific for meningococcal disease: confusion (specificity 98.1\%), photophobia (96.1\%), neck pain/stiffness $(94.3 \%)$, and leg pain (94.3\%). Of the symptoms studied, only confusion $(L R+=24)$, leg pain $(\mathrm{LR}+=7.6)$, photophobia $(\mathrm{LR}+=6.5)$, rash $(\mathrm{LR}+=$ $5.5)$, and neck pain/stiffness $(\mathrm{LR}+=5.3)$ provide clinically useful positive LRs and can be considered as 'red flags' for this illness. Headache, which is often cited as part of the meningitic triad, and pale colour, which had been reported as a potential 'red flag', were both less frequent in children with meningococcal disease than in those with minor febrile infections. Cold hands and feet had a small positive LR of 2.3. 


\section{Strengths and limitations of the study}

The ideal study design for determining the diagnostic characteristics of individual or combinations of symptoms would be a prospective case-control study of children with meningococcal disease and controls with minor infections. However, this was not part of the original meningococcal study, and is now unlikely ever to be undertaken as it would be logistically extremely difficult. The authors believe that the two-sample comparison study design presented here is adequate to guide clinicians involved in first-contact care of children. While it would have been possible to use various analytic techniques to calculate the value of combinations of the presence or absence of certain symptoms (or create a clinical prediction rule), the researchers did not feel that the limitations in the study design and differences in the samples justified this approach. However, the diagnostic characteristics of the symptoms that have been presented are all in children in whom parents also reported the presence of fever, and thus represent simple symptom combinations (for example, fever plus leg pain) that are likely to be remembered by clinicians in practice.

The study has several limitations. First, the children were recruited from 15 practices in relatively more affluent areas of the UK and may not be representative of children whose parents reside in more deprived areas or those who access different types of primary care (for example, telephone triage such as NHS Direct or NHS 24). However, the age range and diagnoses of these children are consistent with similar studies, and unlikely to vary within the UK.

Second, the inclusion criteria for children with acute infection was broad; thus, only 407 of the 924 children recruited actually had a parental report of fever. However, given that almost all children with meningococcal disease present with fever, the authors feel that the group of children with febrile minor infections is the most appropriate comparison group. Parental report of fever, rather than the presence of elevated temperature recorded at the GP surgery was deliberately used to define a febrile illness, partly because GPs recorded a value for temperature only rarely in their records, and also because the authors were confident that most parents are able to identify fever in their child.

Third, the study is open to differential recall bias. Parents in the meningococcal disease study were interviewed a median of 4 months after their child had been admitted to hospital (or died), which could lead to underestimates of symptom frequencies. In contrast, the study data from primary care on minor illnesses were collected at point of care and thus subject to less recall bias. Assuming that the symptoms of interest are more common in children with meningococcal disease, this differential recall would tend to underestimate any differences in symptom frequencies between children with minor infection and those with meningococcal disease. Thus, for most of the symptoms, the study estimates are likely to be conservative.

Fourth, the case-fatality rate-adjusted meningococcal disease symptom frequencies were chosen for the comparison group, rather than observed frequencies. Again, this would tend to underestimate the diagnostic characteristics of most of the symptoms. Finally, the study did not recruit enough young people aged $15-16$ years, and thus it was not possible to determine the diagnostic characteristics of symptoms in this important age group.

\section{Comparison with existing literature}

Parents of children with acute illnesses are often caught in a dilemma of worrying about the possibility of serious infection in their child, while trying to avoid seeking medical help unnecessarily. ${ }^{12-15}$ Symptoms that concern parents the most include fever, cough, rash, change in behaviour, and increased severity of illness, particularly in younger children. ${ }^{12,14}$ The findings of the present study suggest that parents are correct to be worried about rash, photophobia, neck pain/stiffness, or change in behaviour in a febrile child, particularly if the latter involves drowsiness or confusion. However, the authors would add leg pain, and possibly cold hands and feet, to the list of 'red flag' symptoms that should alert parents.

The study data support many of the findings of previous descriptions of the early presentation of meningococcal disease. ${ }^{7,16}$ These consistently show that the pathognomonic haemorrhagic rash is only present in about half of children prior to hospital admission, that most children will have non-specific features, and that classic meningitic symptoms may not be present in the early stage of the illness. ${ }^{7}$ Granier and colleagues' qualitative study of how GPs recognise children with meningococcal disease noted the importance of clinical features that are unusual in children with minor illnesses, such as lethargy, poor eye contact, and altered mental status, as well as pale colour. ${ }^{17}$ In the authors' previous study, the clinical features of cold hands and feet, pale colour, and leg pain were highlighted as early markers of sepsis. ${ }^{1}$

The new results confirm that symptoms of leg pain, confusion, neck pain/stiffness, and photophobia are very rare in children with minor febrile illnesses, while others such as headache and pale colour do not appear to discriminate, and cold hands and feet offer limited discrimination, particularly in infants. It is 
possible that parents' interpretation of pale colour or cold hands and feet was different in the two studies reported here, and that this term is used more as a marker of general illness by parents, rather than indicating poor peripheral circulation.

\section{Implications for clinical practice}

Serious bacterial infections are now extremely rare in economically developed countries. ${ }^{18}$ However, highprofile cases suggest that delayed diagnosis of meningococcal disease still occurs, emphasising the challenge of recognising serious infections in children and young people at an early stage. Parents use a wide variety of sources of information to help guide them when they have a sick child, including their social network, written information, websites, and health professionals. ${ }^{13}$ The findings of this study should be used to strengthen these information sources. It must be acknowledged that the twosample study design was pragmatic, and that the confidence intervals for several of the diagnostic values of symptoms are wide. However, for clinicians, there are surprisingly few published data on the diagnostic value of presenting symptoms.

The findings of the present study should be used as evidence to support (or modify) triage protocols used by telephone, or face to face, by clinicians to guide assessment of children with acute infections. In a child with an acute febrile illness, confusion, leg pain, photophobia, rash, and neck pain/stiffness have clinically useful LRs and, when present, they should usually prompt a face-to-face assessment, unless another cause of these symptoms is obvious. The results of this paper provide evidence for a more targeted approach to identifying febrile children who may be at risk for meningococcal disease.

\section{Funding body}

The study from primary care and the original meningococcal study were funded by grants from the Meningitis Research Foundation (Project 0601.0: Improving the early recognition of meningitis and septicaemia in children and adolescents). The Thames Valley Primary Care Research Partnership also contributed to the funding of the primary care study. The researchers were independent from the funders of the study. The study sponsors had no role in the study design; in the collection, analysis, or interpretation of data; in the writing of the report; or in the decision to submit the article for publication.

\section{Ethics committee}

Ethics approval was obtained from Oxfordshire Research Ethics (Oxon REC C: 07/Q1606/12).

\section{Competing interests}

All authors have completed the unified competing interest form at http://www.icmje.org/coi_disclosure.pdf (available on request from the corresponding author) and declare that (1) no authors have support from any company for the submitted work; (2) no authors have relationships with any companies that might have an interest in the submitted work in the previous 3 years; (3) their spouses, partners, or children have no financial relationships that may be relevant to the submitted work; and (4) Matthew J Thompson and Nelly Ninis have voluntarily assisted the Meningitis Research
Foundation charity in writing and checking their information resources for the general public and clinicians, regarding meningitis and meningococcal disease.

\section{Acknowledgements}

We would like to acknowledge the invaluable assistance of all the parents who completed the questionnaires, as well as GPs and their staff from the participating surgeries in Oxfordshire and Somerset. In particular, we appreciate the assistance and enthusiasm of Calli Smith and the East Somerset Research Consortium. Diane McLeod provided helpful assistance with this study in Oxford. The Department of Primary Health Care is part of the NIHR School of Primary Care Research. Both the primary care study and the meningococcal disease studies were funded by grants from the Meningitis Research Foundation.

\section{Discuss this article}

Contribute and read comments about this article on the Discussion Forum: http://www.rcgp.org.uk/bjgp-discuss

\section{REFERENCES}

1. Thompson MJ, Ninis N, Perera R, et al. Clinical recognition of meningococcal disease in children and adolescents. Lancet 2006; 367(9508): 397-403.

2. Van den Bruel A, Bruyninckx R, Vermeire E, et al. Signs and symptoms in children with a serious infection: a qualitative study. BMC Fam Pract 2005; 6: 36.

3. Trotter CL, Andrews NJ, Kaczmarski EB, et al. Effectiveness of meningococcal serogroup $\mathrm{C}$ conjugate vaccine 4 years after introduction. Lancet 2004; 364(9431): 365-367.

4. Nadel S, Britto J, Booy R, et al. Avoidable deficiencies in the delivery of health care to children with meningococcal disease. J Accid Emerg Med 1998; 15(5): 298-303.

5. Riordan FA, Thomson AP, Sills JA, Hart CA. Who spots the spots? Diagnosis and treatment of early meningococcal disease in children. BMJ 1996; 313(7067): 1255-1256.

6. Sorensen HT, Moller-Petersen J, Krarup HB, et al. Diagnostic problems with meningococcal disease in general practice. J Clin Epidemiol 1992; 45(11): 1289-1293.

7. Granier S, Owen P, Stott NC. Recognizing meningococcal disease: the case for further research in primary care. Br J Gen Pract 1998; 48(429): 1167-1171.

8. National Institute for Health and Clinical Excellence. Feverish illness in children - assessment and initial management in children younger than 5 years. London: National Institute for Health and Clinical Excellence, 2007.

9. Theilen U, Wilson L, Wilson G, et al. Management of invasive meningococcal disease in children and young people: summary of SIGN guidelines. BMJ 2008; 336(7657): 1367-1370.

10. Ninis N, Phillips C, Bailey L, et al. The role of healthcare delivery in the outcome of meningococcal disease in children: case-control study of fatal and non-fatal cases. BMJ 2005; 330(7506): 1475.

11. Davison KL, Crowcroft NS, Ramsay ME, et al. Enhanced surveillance scheme for suspected meningococcal disease in five regional health authorities in England: 1998. Commun Dis Public Health 2002; 5: 205-212.

12. Kai J. What worries parents when their preschool children are acutely ill, and why: a qualitative study. BMJ 1996; 313(7063): 983-986.

13. Kallestrup P, Bro F. Parents' beliefs and expectations when presenting with a febrile child at an out-of-hours general practice clinic. Br J Gen Pract 2003; 53(486): 43-44.

14. Ertmann RK, Soderstrom M, Reventlow S. Parents' motivation for seeing a physician. Scand J Prim Health Care 2005; 23(3): 154-158.

15. Houston AM, Pickering AJ. 'Do I don't I call the doctor': a qualitative study of parental perceptions of calling the GP out-of-hours. Health Expect 2000; 3(4): 234-242.

16. Inkelis SH, O'Leary D, Wang VJ, et al. Extremity pain and refusal to walk in children with invasive meningococcal disease. Pediatrics 2002; 110(1 Pt 1): e3.

17. Granier S, Owen P, Pill R, Jacobson L. Recognising meningococcal disease in primary care: qualitative study of how general practitioners process clinical and contextual information. BMJ 1998; 316(7127): 276-279.

18. Van den Bruel A, Bartholomeeusen S, Aertgeerts B, et al. Serious infections in children: an incidence study in family practice. BMC Fam Pract 2006; 7: 23 . 